\title{
BCMF Regimen
}

National Cancer Institute

\section{Source}

National Cancer Institute. BCMFRegimen. NCI Thesaurus. Code C161914.

A chemotherapy regimen consisting of bleomycin, cyclophosphamide, fluorouracil and methotrexate that may be used in the treatment of certain head and neck cancers. 